\title{
Consumer Identity and Loyalty in Electronic Product Offline Brand Operation: The Moderator Effect of Fanship
}

\author{
Yitao Chen ${ }^{1,2}$, Haijian Wang ${ }^{1, *}$, Lei Wang ${ }^{1}\left(\mathbb{D}\right.$ and Jianyi Ding ${ }^{1}$ \\ 1 School of Business, Guilin University of Electronic Technology, Guilin 541004, China; \\ ace_chen88@mails.guet.edu.cn (Y.C.); wangleisss@guet.edu.cn (L.W.); dingjianyi0508@gmail.com (J.D.) \\ 2 Management School, Hainan University, Haikou 570228, China \\ * Correspondence: wanghj@guet.edu.cn; Tel.: +86-13507730538
}

Citation: Chen, Y.; Wang, H.; Wang, L.; Ding, J. Consumer Identity and Loyalty in Electronic Product Offline Brand Operation: The Moderator Effect of Fanship. Information 2021, 12, 282. https://doi.org/10.3390/ info12070282

Academic Editors: Umair Akram, Jiayin Qi and Nada Trunk Širca

Received: 15 June 2021

Accepted: 13 July 2021

Published: 16 July 2021

Publisher's Note: MDPI stays neutral with regard to jurisdictional claims in published maps and institutional affiliations.

Copyright: (c) 2021 by the authors. Licensee MDPI, Basel, Switzerland. This article is an open access article distributed under the terms and conditions of the Creative Commons Attribution (CC BY) license (https:// creativecommons.org/licenses/by/ $4.0 /)$.

\begin{abstract}
Continuous enhancements of the intelligence of electronic products can lead to the homogenization of products and innovation of offline experiential marketing modes. The diversified development of brand sales channels is inevitable, to fulfill the diversified shopping demands of consumers. Based on 226 valid questionnaires, this study conducts empirical research with SPSS and AMOS to examine the impact of experience characteristics on consumer brand identity and brand loyalty. Then, the fanship consumer attribute is added to conduct path-moderating analysis. The results illustrated the following: (a) consumers act and relate experiences, which affects brand cognitive identity; thinking, acting, and relating experiences positively affect brands' emotional identity; (b) cognitive identity and emotional identity can jointly create brand loyalty, and play a partial mediating role between offline experience and brand loyalty. Finally, the higher the fanship, the higher the consumer identity and the higher the brand loyalty. Overall, this study provides a certain basis for decision-making and suggestions for the offline operation of electronic brands.
\end{abstract}

Keywords: experience characteristics; brand identify; brand loyalty; brand fanship

\section{Introduction}

Smart products are increasingly being integrated into the surroundings and life of consumers, providing more convenience to life. However, electronic products embodying intelligence differ from other products, in that their real value and the corresponding psychological expectation cannot be felt through virtual experience. For example, when buying clothes online, you can feel what you are wearing through virtual experience; when buying food online, you can experience its taste virtually; when buying daily necessities, you can feel their convenience through the display. However, the virtual experience mode of smart electronic products cannot provide a matching psychological expectation to consumers. The offline experience, however, can not only effectively prevent the differentiation of psychological expectations, but also decreases the psychological gap in consumers' cognition of products.

With the rapid growth of the Internet, the convenience of the online experience no longer attracts consumers, and smart electronic products are no longer smart tools with a kernel and chip architecture, but high-tech technologies that can offer consumers a true perception. In addition to smart electronic products, many enterprises focusing on online business also realize the significance of experiential marketing and launch offline experience shops. Based on big data, artificial intelligence, and other advanced technologies and equipment, Alibaba built a new retail supermarket for fresh food distribution: Freshhema. Three squirrels in the snack industry have created offline stores with the help of experience, which rapidly increases the brand's influence, making it a household name. While there is an increase in the sale of e-books, and paper-printed books are declining, Dangdang has opened physical bookstores with the help of an offline experience space. In the electronic industry, Xiaomi can be used as an example. In 2017, Xiaomi Home was present in 170 cities, 
and the number of stores exceeded 1000 in 2020, providing services to hundreds of millions of consumers. The leading reason for the rapid expansion of these enterprises from online to offline lies in the offline business model, focusing on experience.

With the swift advancement in the mobile Internet and the continuous upgrades to consumer demand, the diversification of brand sales channels has become an inevitable way of marketing. Online shopping has advantages such as information symmetry, its fast and convenient nature, and home delivery, whereas offline experience stores use new technologies to provide consumers with an all-round experience paradigm, including offline scenes, consumer perception, big data support, and other aspects; this experience paradigm enables offline shopping to become a comprehensive space integrating product sales, entertainment experience, and brand communication. Currently, the experience economy has driven consumers to alter their consumption mode. Consumers focusing on the on-the-spot shopping experience have brought online consumption, deeply rooted in the Internet, offline. There are many advantages to the experience of physical stores, and new advantages continue to emerge. Integrating consumption into experience has become a part of value exchange. Even if a product is not sold, it still represents a kind of display of the brand itself, helping to understand its widespread popularity.

This study takes the offline shops of mainstream electronic brands such as Huawei, Xiaomi, and Apple as the research objects, collects data from consumers with offline experience using the questionnaire survey, and empirically analyzes the impact of offline experience characteristics on brand identity and brand loyalty. The specific contents are as follows: this study investigates: (i) the impact of offline experience characteristics of different dimensions on brand identity (cognitive identity vs. emotional identity); (ii) the mediating effect of cognitive identity and emotional identity on brand loyalty in the process of consumers' offline experience; (iii) the moderating role of consumer fan characteristics in the research path. This study will construct a theoretical model of experience characteristics, brand identity, brand loyalty, and fanship. The research conclusions upgrade the structural relationship of offline experience theory to some extent, which will provide theoretical guidance for the development and operation of offline channels of smart electronic brands.

\section{Literature Review}

\subsection{Experiential Marketing}

Alvin Toffler, who proposed the word "experience" in 1970, highlighted that experience is the product of the psychologization of goods and services, and a new form of future economic development. Holbrook and Hirschman [1] applied the concept of experience to the field of marketing and used it to elucidate consumer behavior. This gradually became the core concept in the field of consumer behavior. Pine and Gilmore [2] categorized experience into entertainment experience, education experience, aesthetic experience, and reclusive experience, based on the content of the experience. Schmitt [3] claimed that experiential marketing is a marketing and management mode driven by experience, which can be categorized into such five experience dimensions: sense, feel, think, act, and relate.

Traditional offline marketing is predominated by product sales. Before purchasing goods, consumers usually collect and screen a large amount of goods and enterprise information, and then make rational purchase decisions through rational judgment. Nevertheless, experiential marketing is a type of marketing mode that takes consumers as the leading factor and effectively combines the scene of offline space, experience, and Vmodern technology, such that customers can interact with products and product providers effectively and recognize the value of products or services through this interaction [4]. Bruwer, J. and K. Alant (2009) looked at the experiential marketing of wine tourism, finding that enterprises with different positionings should adopt different experiential strategies [5]. Dressler, Marc. and Paunovic, Ivan (2019), from the perspective of tourists' experience in wine bars, suggested that the experience process design should be highly related to the product [6]. 
The service scope of offline experience is not only in the product itself, but also a type of cultural display. Through the display of diversified experience and the integration of product and facility functions, the brand's creativity and ideas are conveyed to consumers, producing immersive psychological feelings and leading them to make decisions. Together with the consumption experience, consumers focus on the shopping experience of the sense of presence, aiming to integrate this experience into their shopping, gaining the sense of value and pleasure, and making the experience a service and value exchange. Therefore, the experience itself becomes a type of consumable commodity.

Conversely, the offline experience, predominated by consumers, breaks the characteristics of online shopping virtualization, fulfills the personalized consumption needs of consumers, integrates the experience characteristics into the shopping mode, and creates a shopping environment where consumers' needs are supreme. Schmitt [3] highlighted that offline shops integrated with experience characteristics could better satisfy the shopping and aesthetic needs of consumers, provide sensory stimulation to consumers, and attain the perfect marketing purpose, which is a brand-new marketing mode. Taking the offline shops of mainstream electronic brands such as Xiaomi, Huawei, and Apple as the research objects, and referring to the five-dimension module of experiential marketing proposed by Schmitt [3], in which the sense experience, feel experience, and think experience are three dimensions of consumers' self-experience, and the act experience and relate experience are two dimensions of consumers' interactive shared experience with others, this study explores the impact of the experience characteristics of e-brand offline shops on their brand identity.

\subsection{Brand Identity and Loyalty}

Identity belongs to the category of sociology, and the concept of brand identity is based on the theory of emotional identity, which has been broadly applied in many disciplines [7]. Jenkins (1996) highlighted that identity is generated when individuals define themselves as a specific organization, in line with their image, and distinguish themselves from others. From the perspective of psychology, Chen and Lu [8] highlighted that identity is a psychological process, in which an individual is influenced by a certain characteristics of others, transforms the content of this aspect, and produces a sense of personality or self. Lam et al. [9] claimed that brand identity is a type of psychological state; by understanding and evaluating a certain brand, customers psychologically belong to the brand, and obtain a sense of psychological unity with the brand. In addition, brand identity is also a business and consumer category, Urde, M. and S. A. Greyser (2016) studied the impact of the Nobel Prize to determine which factors contribute to its high level of brand identity [10]. Furthermore, Dressler, M. and I. Paunovic (2021), based on an analysis of textual data from German wineries' websites and reviews, found words were highly correlated with brand identity [11].

The research on brand identity is multidimensional. Ashforth and Mael [12], Jin [13] both divided this identity into cognitive identity and emotional identity. As they are fastmoving consumer goods, upgrading electronic products has become one of the objectives of that consumers, and brand identity forms the basis of brand loyalty. Offline experience provides a way for consumers to understand the brand. This study introduces cognitive identity and emotional identity to the offline experience. Brand identity is produced through consumers' all-round experience and actual contact with products, and the social resonance of the brand is produced on the basis of act and relate experiences, with the objective of offline experience marketing.

\subsection{Brand Fanship}

The Chinese word "粉丝" stems from the English word "fans." Fans are not only supporters of the brand, but also the communicators of the brand's word-of-mouth, and the pronoun of fashion. Apple's "Apple fans" were the first to witness the power of fans, followed by Xiaomi's "Mi fans" and Huawei's "Hua fans." A high number of fans started 
to appear for all types of fresh and fashionable products. Gong and Su [14] highlighted that the success of fans' marketing is based on fans' identity as a cultural symbol and their emotional identity. The new technology, scene, and all-round experience paradigm of offline experience has shattered the virtualization characteristics of online contact products, and interaction and real-time sharing between fans became more efficient, as well as providing new fans, with a way to comprehend the brand and enhance the initiative of consumer experience.

\section{Theoretical Model and Hypotheses}

\subsection{Model}

The experience economy aids in promoting the rapid progress of offline marketing, fulfilling the different shopping needs of consumers and facilitating the offline activity and communication of brands. Using the offline shops of electronic brands as the research object, this study discusses the potential mechanisms that influence the offline experience characteristics regarding brand loyalty, using the five-dimension module of offline experience characteristics as the independent variable and the brand identity as the media variable. It also introduces fanship as a way of testing the mediating role of the experience path. Figure 1 shows the research model.

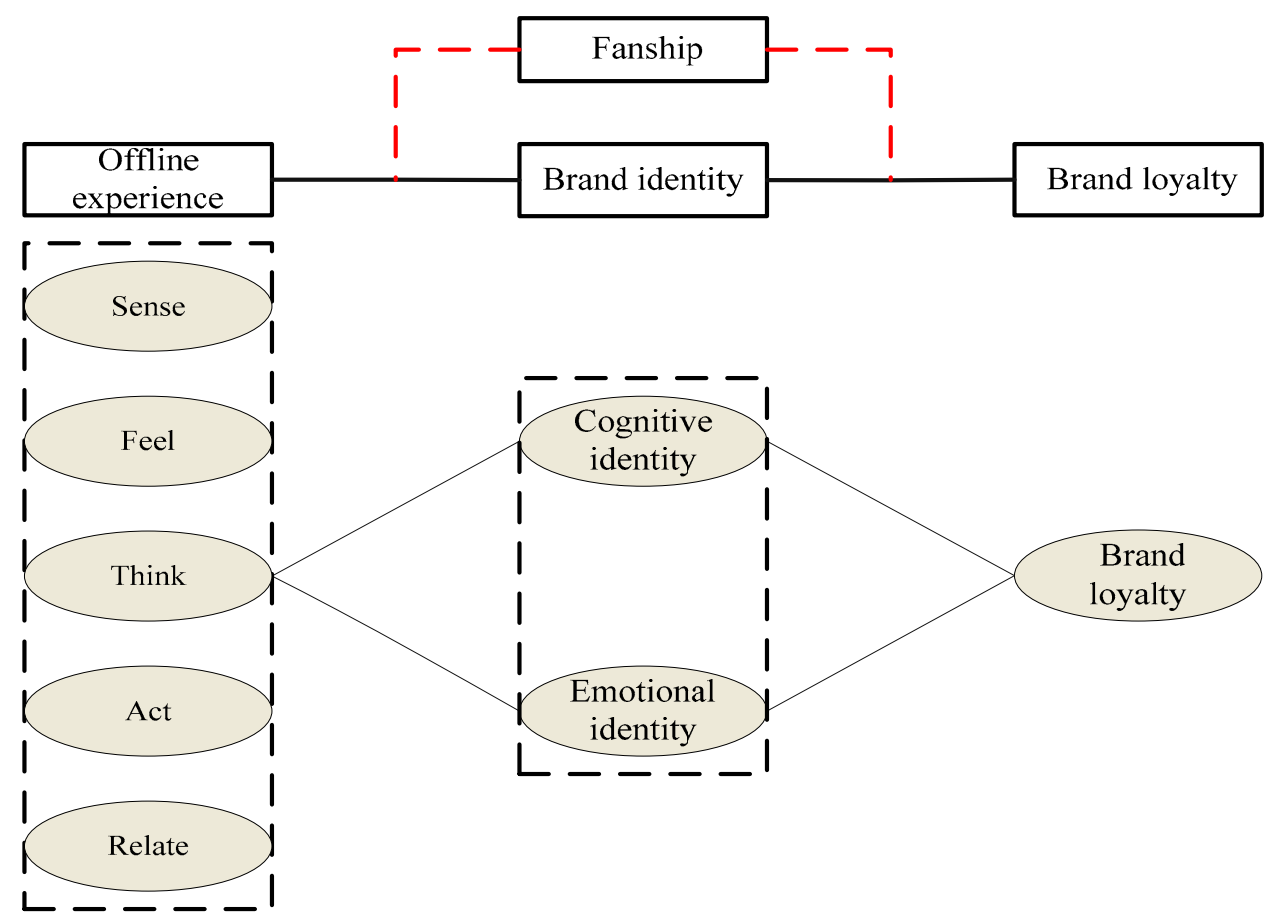

Figure 1. Research concept model.

\subsection{Hypotheses}

(1) Offline experience and brand identify

The five-dimension experience module possesses the shared experience mode of consumers' self-experience and their interaction with others, which can fully meet consumers' various psychological needs. With a more convincing personal experience, consumers can better understand the brand. Alba and Hutchinson [15] claimed that experience can allow consumers to generate familiarity with products or matters, brand association, and product impression, and can fortify the relationship between individuals and brands. Aaker [16] highlighted that the key to consumers generating a brand identity for products and services is the process of experience. Schmitt [3] emphasized that consumers are both rational and social in the process of consumption, and offline scenes must induce the relate experience of consumers to obtain personal and social recognition. Zheng and Huang [17] suggested 
that, in the virtual brand community, social, think, act, and relate consumption experiences exert a positive impact on brand identity. Cui and Chen [18], in an empirical study of offline experience and perceived value, pointed out that entertainment and aesthetic experience affect the function and social value, while educational experience affects the social value. As the five-dimension experience module is a multifaceted experience mode, this study claims that it will produce different brand identities for consumers. Hence, we assumed the following:

Hypothesis 1 (H1). Offline experience characteristics (sense, feel, think, act, and relate) affect consumers' cognitive identity of brands.

Hypothesis 2 (H2). Offline experience characteristics (sense, feel, think, act, relate) affect consumers' emotional identity of brands.

\section{(2) Brand identity and brand loyalty}

Loyalty at is the core of brand development. When a product fulfills the needs of consumers, consumers will gain a sense of social and behavioral identity. Thus, brand loyalty is directly affected by brand identity. The higher the brand identity, the higher the consumers' trust, and subsequent purchase and loyalty levels [19]. Brand identity is the consumers' perception of consistency between the self and the image and concept of the brand. When a brand is associated with a positive image, consumers will respond when in need, namely with acceptance and recognition.

Through sensory self-experience, consumers perceive a fit between the self and brand concept, and, therefore, produce the cognitive identity of the brand and increase their intention to purchase. Alternatively, customers usually share their shopping experience with their peers offline, so that real and potential customers gain social resonance and emotional identity, which eventually aids in attaining brand loyalty. This study takes two dimensions of brand identity into account in the empirical research, namely cognitive identity and emotional identity. To comprehend the difference between a brand identity of different dimensions and brand loyalty, the following hypotheses are proposed:

Hypothesis 3 (H3). Consumers' cognitive identity of brands will improve brand loyalty.

Hypothesis 4 (H4). Consumers' emotional identity of brands will improve brand loyalty.

(3) The mediating role of brand fans

Lee et al. [19], in their research on brand loyalty, highlighted that the higher the fanship, the higher the willingness to recommend the brand, the stronger the driving effect on potential users, and the lower the likelihood of customer churn. Pentecost and Andrews [20], in their research on fashion retail, claimed that consumer actions would also differ based on the level of fans, enthusiasm, excitement, and dedication. Thus, fan marketing implies a large amount of user information, which can be used to execute precision marketing. Mastering the preferences and aesthetic pursuits of existing fans could stimulate the initiatives of experience and positive Internet word-of-mouth. In addition, existing fans will drive potential users to have better interactions and increase the marketing effect of interactive experience. Hence, the following hypothesis is proposed:

Hypothesis 5 (H5). The higher the fanship, the higher the influence of brand identity on brand loyalty.

\section{Research Design and Empirical Analysis}

\subsection{Scale Design and Sample Data Collection}

The scale used in this study was based on previous research and modified or adapted as per the requirements, based on a mature scale. The Likert 5-point scale was adopted. The study by Schmitt [3] was used for experience characteristics; the brand identify referred 
to Wolter et al. (2017). The brand loyalty referred to Jiang et al. (2008), and fanship referred to Park and Chen (2019). The questionnaire data were collected from young people with a relatively wide range of contact with smart electronic products. In March 2021, a total of 240 questionnaires were collected through network media such as WJX (https:/ / www.wjx.cn/, accessed on 1-14 March 2021), and 14 invalid questionnaires were excluded, with an effective rate of $94 \%$. Demographic information is shown in Table 1.

Table 1. Sample descriptive statistics.

\begin{tabular}{|c|c|c|c|c|c|c|c|}
\hline Classification & Indicators & Number & Rate (\%) & Classification & Indicators & Number & Rate (\%) \\
\hline \multirow{2}{*}{ Gender } & Male & 68 & 30.1 & \multirow{5}{*}{ Professional } & Students & 154 & 68.1 \\
\hline & Female & 158 & 69.9 & & Company employees & 51 & 22.6 \\
\hline \multirow{6}{*}{ Age } & $20 \square$ & 40 & 17.7 & & Civil servants & 12 & 5.3 \\
\hline & $20-25$ & 117 & 51.8 & & self-employed & 5 & 2.2 \\
\hline & $26-30$ & 35 & 15.5 & & Others & 4 & 1.8 \\
\hline & $31-35$ & 19 & 8.4 & \multirow{6}{*}{ Monthly income } & 2000 the following & 102 & 45.1 \\
\hline & $36-40$ & 14 & 6.2 & & $2001-3000$ & 38 & 16.8 \\
\hline & ${ }^{41} \square$ & 1 & 0.4 & & $3001-5000$ & 32 & 14.2 \\
\hline \multirow{8}{*}{$\begin{array}{l}\text { Offline } \\
\text { experience } \\
\text { brand }\end{array}$} & HUAWEI & 35 & 15.5 & & $5001-8000$ & 20 & 8.8 \\
\hline & vivo & 81 & 35.8 & & $8001-10,000$ & 18 & 8 \\
\hline & Apple & 21 & 9.3 & & More than 10,000 & 16 & 7.1 \\
\hline & OPPO & 67 & 29.6 & \multirow{5}{*}{$\begin{array}{l}\text { The degree of } \\
\text { education }\end{array}$} & $\begin{array}{l}\text { Junior high school } \\
\text { graduation }\end{array}$ & 6 & 2.7 \\
\hline & MI & 7 & 3.1 & & $\begin{array}{l}\text { Graduated from } \\
\text { high school }\end{array}$ & 22 & 9.7 \\
\hline & Samsung & 4 & 1.8 & & Graduated from college & 19 & 8.4 \\
\hline & Meizu & 10 & 4.4 & & $\begin{array}{l}\text { Undergraduate course } \\
\text { graduation }\end{array}$ & 132 & 58.4 \\
\hline & Others & 1 & 0.4 & & Postgraduate or above & 47 & 20.8 \\
\hline
\end{tabular}

\subsection{Reliability and Validity Test}

In this study, Cronbach $\alpha$ coefficient, $C R$ value, and AVE value were used to test the reliability of the model (Table 2). In addition, confirmatory factor analysis was adopted to test the construct validity of the measurement model. Model fitting was as follows: $\chi^{2} / \mathrm{df}=1.166 ; \mathrm{RMR}=0.024 ; \mathrm{AGFI}=0.878 ; \mathrm{RMSEA}=0.027 ; \mathrm{NFI}=0.915 ; \mathrm{CFI}=0.987 ;$ $\mathrm{PNFI}=0.753$. The factor load of each variable was $>0.5, \mathrm{CR}$ value was $>0.7$, and the square root of AVE of each variable was greater than the absolute value of the correlation coefficient, suggesting a good validity level (Table 3).

\subsection{Hypothesis Test}

Before the hypothesis test, the structural equation model was tested for its fitting, and the results showed the following: $\chi^{2} / \mathrm{df}=1.225 ; \mathrm{RMR}=0.032 ; \mathrm{GFI}=0.900 ; \mathrm{AGFI}=0.872$; RMSEA $=0.032 ; \mathrm{NFI}=0.908 ; \mathrm{CFI}=0.982 ; \mathrm{TLI}=0.978 ; \mathrm{IFI}=0.982 ;$ and PNFI $=0.766$. As each fitting index was close to the standard value, the structural equation model had good fitting.

Besides this, the hypothesis relationship was tested by the path standardization coefficient of the structural equation; Table 4 depicts the results. The act experience $(\beta=0.295, p<0.001)$ and relate experience $(\beta=0.458, p<0.001)$ had a positive impact on consumers' cognitive identity, thereby supporting hypothesis 1 . In addition, the think experience $(\beta=0.202, p<0.050)$, act experience $(\beta=0.211, p<0.050)$, and relate experience $(\beta=0.221, p<0.050)$ had a positive impact on consumers' emotional identity; hence, 
hypothesis 2 holds. Both cognitive identity $(\beta=0.436, p<0.001)$ and emotional identity $(\beta=0.269, p<0.001)$ had an influence on brand loyalty; hence, hypotheses 3 and 4 hold.

Table 2. Reliability Analysis.

\begin{tabular}{|c|c|c|c|c|c|}
\hline Factor & Variable & Standardization Estimate & AVE & CR & Cronbach $\alpha$ \\
\hline Se3 & \multirow{3}{*}{ Sense experience } & 0.798 & \multirow{3}{*}{0.769} & \multirow{3}{*}{0.908} & \multirow{3}{*}{0.831} \\
\hline Se2 & & 0.818 & & & \\
\hline Se1 & & 0.745 & & & \\
\hline $\mathrm{Fe} 3$ & \multirow{3}{*}{ Feel experience } & 0.812 & \multirow{3}{*}{0.755} & \multirow{3}{*}{0.902} & \multirow{3}{*}{0.842} \\
\hline $\mathrm{Fe} 2$ & & 0.829 & & & \\
\hline $\mathrm{Fe} 1$ & & 0.769 & & & \\
\hline $\mathrm{Te} 3$ & \multirow{3}{*}{ Think experience } & 0.783 & \multirow{3}{*}{0.709} & \multirow{3}{*}{0.879} & \multirow{3}{*}{0.809} \\
\hline $\mathrm{Te} 2$ & & 0.731 & & & \\
\hline $\mathrm{Te} 1$ & & 0.781 & & & \\
\hline Ae3 & \multirow{3}{*}{ Act experience } & 0.758 & \multirow{3}{*}{0.729} & \multirow{3}{*}{0.889} & \multirow{3}{*}{0.815} \\
\hline Ae2 & & 0.769 & & & \\
\hline Ae1 & & 0.788 & & & \\
\hline $\operatorname{Re} 3$ & \multirow{3}{*}{ Relate experience } & 0.907 & \multirow{3}{*}{0.816} & \multirow{3}{*}{0.93} & \multirow{3}{*}{0.911} \\
\hline $\operatorname{Re} 2$ & & 0.882 & & & \\
\hline $\operatorname{Re} 1$ & & 0.852 & & & \\
\hline $\mathrm{CI} 3$ & \multirow{3}{*}{ Cognitive identity } & 0.874 & \multirow{3}{*}{0.821} & \multirow{3}{*}{0.932} & \multirow{3}{*}{0.878} \\
\hline $\mathrm{CI} 2$ & & 0.783 & & & \\
\hline CI1 & & 0.871 & & & \\
\hline EI3 & \multirow{3}{*}{ Emotional identity } & 0.901 & \multirow{3}{*}{0.818} & \multirow{3}{*}{0.931} & \multirow{3}{*}{0.923} \\
\hline EI2 & & 0.888 & & & \\
\hline EI1 & & 0.895 & & & \\
\hline BL4 & \multirow{4}{*}{ Brand loyalty } & 0.771 & \multirow{4}{*}{0.760} & \multirow{4}{*}{0.926} & \multirow{4}{*}{0.855} \\
\hline BL3 & & 0.757 & & & \\
\hline BL2 & & 0.796 & & & \\
\hline BL1 & & 0.767 & & & \\
\hline
\end{tabular}

Table 3. Validity test.

\begin{tabular}{|c|c|c|c|c|c|c|c|c|}
\hline Item & Sense & Feel & Think & Act & Relate & Cognitive Identity & Emotional Identity & Loyalty \\
\hline Sense & 0.769 & & & & & & & \\
\hline Feel & 0.550 & 0.755 & & & & & & \\
\hline Think & 0.500 & 0.506 & 0.709 & & & & & \\
\hline Act & 0.341 & 0.379 & 0.331 & 0.729 & & & & \\
\hline Relate & 0.182 & 0.314 & 0.257 & 0.008 & 0.816 & & & \\
\hline Cognitive identity & 0.374 & 0.375 & 0.421 & 0.331 & 0.306 & 0.821 & & \\
\hline Emotional identity & 0.135 & 0.244 & 0.228 & 0.280 & 0.454 & 0.279 & 0.818 & \\
\hline Loyalty & 0.372 & 0.428 & 0.337 & 0.390 & 0.361 & 0.487 & 0.376 & 0.760 \\
\hline
\end{tabular}


Table 4. Structural equation path results.

\begin{tabular}{|c|c|c|c|c|c|c|}
\hline & Path & & Standardization Estimate & S.E. & CR & $p$ \\
\hline Sense & $\rightarrow$ & \multirow{5}{*}{$\begin{array}{c}\text { Cognitive } \\
\text { identity }\end{array}$} & -0.072 & 0.140 & -0.795 & 0.427 \\
\hline Feel & $\rightarrow$ & & 0.009 & 0.125 & 0.090 & 0.928 \\
\hline Think & $\rightarrow$ & & 0.049 & 0.130 & 0.553 & 0.580 \\
\hline Act & $\rightarrow$ & & 0.295 & 0.128 & 3.659 & 0.000 \\
\hline Relate & $\rightarrow$ & & 0.458 & 0.076 & 6.339 & 0.000 \\
\hline Sense & $\rightarrow$ & \multirow{5}{*}{$\begin{array}{c}\text { Emotional } \\
\text { identity }\end{array}$} & 0.140 & 0.099 & 1.518 & 0.129 \\
\hline Feel & $\rightarrow$ & & 0.059 & 0.088 & 0.618 & 0.537 \\
\hline Think & $\rightarrow$ & & 0.202 & 0.093 & 2.210 & 0.027 \\
\hline Act & $\rightarrow$ & & 0.211 & 0.088 & 2.637 & 0.008 \\
\hline Relate & $\rightarrow$ & & 0.221 & 0.052 & 3.100 & 0.002 \\
\hline Cognitive identity & $\rightarrow$ & \multirow{2}{*}{ Brand loyalty } & 0.436 & 0.060 & 5.842 & 0.000 \\
\hline Emotional identity & $\rightarrow$ & & 0.269 & 0.039 & 3.869 & 0.000 \\
\hline
\end{tabular}

\subsection{Fanship Moderating Test}

Fanship is imported into the study to test the path moderating the research model. Based on the method used by Sun et al. (2020), the average value of consumer's fanship measurement items was recentralized, and the high $(5.1276(\mathrm{SD}=0.604, \mathrm{~N}=126)$ ) and low (3.5912 ( $\mathrm{SD}=0.724, \mathrm{~N}=100)$ ) fanship scores were introduced into the structural equation model. Moreover, the model fitting index and internal consistency index were in a good range. Then, the path coefficients were compared. Table 5 depicts the detailed results.

Table 5. Results of moderating analysis.

\begin{tabular}{|c|c|c|c|c|c|}
\hline \multirow{3}{*}{ Path } & \multicolumn{4}{|c|}{ Fanship } & \multirow{3}{*}{ CR } \\
\hline & \multicolumn{2}{|c|}{$\begin{array}{c}\text { Low: } 3.5912 \\
(\mathrm{SD}=0.724, \mathrm{~N}=100)\end{array}$} & \multicolumn{2}{|c|}{$\begin{array}{c}\text { High: } 5.1276 \\
(\mathrm{SD}=0.604, \mathrm{~N}=126)\end{array}$} & \\
\hline & Estimate & $p$ & Estimate & $p$ & \\
\hline Sense $\rightarrow$ Cognitive identity & 0.019 & 0.870 & 0.262 & 0.060 & 1.364 \\
\hline Sense $\rightarrow$ Emotional identity & -0.099 & 0.425 & -0.112 & 0.341 & -0.421 \\
\hline Feel $\rightarrow$ Cognitive identity & 0.238 & 0.054 & -0.095 & 0.508 & -1.828 \\
\hline Feel $\rightarrow$ Emotional identity & 0.117 & 0.364 & -0.150 & 0.227 & -1.511 \\
\hline Thin $\rightarrow$ Cognitive identity & 0.032 & 0.789 & 0.377 & 0.010 & 2.137 \\
\hline Think $\rightarrow$ Emotional identity & -0.148 & 0.239 & 0.214 & 0.075 & 2.093 \\
\hline Act $\rightarrow$ Cognitive identity & 0.215 & 0.068 & 0.154 & 0.163 & -0.454 \\
\hline Act $\rightarrow$ Emotional identity & 0.316 & 0.013 & 0.334 & 0.000 & 1.072 \\
\hline Relate $\rightarrow$ Cognitive identity & 0.299 & 0.003 & 0.071 & 0.505 & -1.528 \\
\hline Relate $\rightarrow$ Emotional identity & 0.248 & 0.019 & 0.650 & 0.000 & 4.348 \\
\hline Cognitive identity $\rightarrow$ loyalty & 0.348 & 0.002 & 0.455 & 0.000 & 2.630 \\
\hline Emotional identity $\rightarrow$ loyalty & 0.189 & 0.079 & 0.318 & 0.000 & -2.069 \\
\hline
\end{tabular}

In the path of think experience and cognitive identity, $\beta$ values in low fanship and high fanship samples were $0.032(p=0.789)$ and $0.377(p<0.010)$, respectively; the critical ratio of the difference between the two parameters was 2.137, and its absolute value was greater than \pm 1.965 , which indicates that the difference between the corresponding parameters of the two groups reaches a significant level of 0.05 , and the moderating effect was highly 
significant. In the path of cognitive identity and brand loyalty, $\beta$ values in low fanship and high fanship samples were $0.348(p<0.010)$ and $0.455(p<0.001)$. The critical ratio of the difference between the two parameters was 2.630, and its absolute value was greater than \pm 1.965 , suggesting that the difference between the corresponding parameters of the two groups reached a significant level of 0.010 , and the moderating effect was very significant. In the path of emotional identity and brand loyalty, $\beta$ values in low fanship and high fanship samples were $0.189(p=0.079)$ and $0.318(p<0.001)$; the critical ratio of the difference between the two parameters was -2.069 , and its absolute value was greater than \pm 1.965 , implying that the difference between the corresponding parameters of the two groups reached a significant level of 0.001 , and the moderating effect was very significant. Overall, the higher the fanship of consumers in the high fanship group the consumers in the low fanship group, the higher the influence of brand identity on brand loyalty. Hence, hypothesis 5 is verified.

\section{Research Conclusions and Management Implications}

In recent years, there have been many examples of brands moving offline to thrive using experience in the field of experiential marketing. However, there is a dire need to research the offline marketing path, and the interaction mechanism between paths needs to be expanded. Taking well-known domestic e-brand offline shops as the object, this research empirically explored the causal relationship among experience characteristics, brand identity, and brand loyalty to test the moderating effect of the research path, taking consumers' fanship for the brand as the moderating variable. Specific results are as follows.

First, in the process of consumers' online experience, the act and relate experiences have a positive impact on the brand's cognitive identity. The think experience, act experience, and relate experience exert a positive impact on the brand's emotional identity. Thus, to attain the effect of offline experience, consumers' shared experience items will be strengthened to enhance consumer stickiness and accomplish the goal of brand loyalty. Alternatively, the self-experience items in consumers' think, act, and relate experiences will be enhanced to increase the diversity of consumers' self-experience, decrease the experience of homogenization among similar brands, and create a unique experience space for brands. Meanwhile, the offline experience will be expanded from the perspective of brand culture and brand communication by combining high-tech means (such as artificial intelligence, big data, and intelligent simulation) and personalized services. In addition, the sense experience and feel experience characteristics were not validated for the hypotheses of cognitive identity and emotional identity. Perhaps the offline experience lacks the content that can stimulate the emotional pain points of consumers, and even lacks the sensory stimulation of unique content, so that a sense of personal and emotional identity cannot be produced through consumers' sense and feel experiences. Alternately, the offline stores of electronic brands may be too technology-oriented and lack sense and feel elements, resulting in a failure to reach the expected experience level.

Second, through experience, consumers' cognitive identity and emotional identity regarding the brand exert a positive impact on brand loyalty. Moreover, cognitive identity and emotional identity exert a partial mediating effect on brand experience and loyalty. In traditional offline marketing, stores are only trading places, while, for consumers, the diversified space, based on experience, not only increases consumers' brand cognition but also closely connects brands with consumers. By rationally and sensibly examining the needs of consumers, personal experience and shared experience are organically combined, and consumers' cognitive identity and emotional identity are investigated to attain the goal of brand loyalty. In addition, act and relate experiences are used to stimulate consumers to share and connect with the brand, based on which consumers' activity and drive are stimulated to create brand loyalty in potential customers. Conversely, the offline experience can augment the brand identity of consumers, and brand identity is a crucial way to enhance brand loyalty. Cognitive identity is the organic unity of consumer personality and brand personality, whereas emotional identity is the performance of group identity and the 
key to increasing brand value. Hence, as a mediator between brand experience and brand loyalty, the role of brand identity cannot be overlooked.

Third, fanship plays a significant moderating role among the experience characteristics, brand identity, and brand loyalty. Fans of a brand have a higher symbolic identity and emotional identity, and support and pursuit of the brand is their way of expressing loyalty. Fans' initiative to acquire brand information, their efficient communication ability, and the driving force of popular culture are also crucial ways of creating potential customers. In the process of experience, fans' cognitive identity and brand loyalty are higher than potential users, based on their understanding of the brand. Thus, the positive experience of fans will be reasonably promoted to drive the transformation from potential users to fan users.

\section{Future Research Directions}

In this study, most hypotheses were verified through data analysis. However, some shortcomings are present, owing to the limitations of data collection and idea derivation. First, offline shops involve a wide range of industries. The experience shops of electronic products were selected in this study, and there are some limitations in the selection content. In addition, differences were present in the internal and external experience characteristics between electronic brands. Next, the content of different products can be comparatively analyzed according to type and brand. Second, the scale uses a previous study for reference, a commonly used dimension. Special content can be added in a follow-up study for verification, per the need to further improve and enrich the model mechanism. Finally, the sample descriptive statistics used in this study could play a better role, and follow-up control analysis could be performed for the research model based on consumer characteristics.

Author Contributions: Conceptualization, Y.C.; Formal analysis, Y.C.; Methodology, Y.C.; Writingoriginal draft, Y.C.; Funding acquisition, H.W.; Resources, H.W.; Supervision, H.W.; Validation, L.W.; Visualization, L.W.; Project administration, L.W.; Data curation, J.D.; Investigation, J.D.; Writingreview \& editing, J.D. All authors have read and agreed to the published version of the manuscript.

Funding: This research was funded by the project for enhancing basic scientific research ability of young and middle-aged teaching staff in Guangxi Universities, grant number: 2021KY0194. And the project of scientific research foundation of Guilin University of Electronic Technology, grant number: US20059Y.

Institutional Review Board Statement: Not applicable.

Informed Consent Statement: Informed consent was obtained from all subjects involved in the study.

Data Availability Statement: The data that support the findings of this study are available on request from the corresponding author. The data are not publicly available due to privacy or ethical restrictions.

Conflicts of Interest: The authors declare no conflict of interest.

\section{References}

1. Holbrook, M.B.; Hirschman, E.C. Experiential Aspects of Consumption: Consumer Fantasies, Feelings, and Fun. J. Consum. Res. Oxf. 1982, 9, 132-140. [CrossRef]

2. Pine, B.J.; Gilmore, J.H. Welcome to the Experience Economy. Harv. Bus. Rev. 1998, 76, 97-105. [PubMed]

3. Schmitt, B. Experiential marketing. J. Mark. Manag. 1999, 15, 53-67. [CrossRef]

4. LaSalle, D.; Britton, T.A. Priceless: Turning Ordinary Products into Extraordinary Experiences; Harvard Business School Press: Boston, MA, USA, 2003; pp. 88-137.

5. Bruwer, J.; Alant, K. The hedonic nature of wine tourism consumption: An experiential view. Int. J. Wine Bus. Res. 2009, 21, 235-257. [CrossRef]

6. Dressler, M.; Paunovic, I. Customer-centric offer design: Meeting expectations for a wine bar and shop and the relevance of hybrid offering components. Int. J. Wine Bus. Res. 2019, 31, 105-127. [CrossRef]

7. Brewer, M.B. The social self: On being the same and different at the same time. Personal. Soc. Psychol. Bull. 1991, 17, 475-482. [CrossRef]

8. Chen, C.; Lu, C. Identity: A New Perspective in the Study of Tourism Experience. Tour. Trib. 2011, 26, 37-42. 
9. Lam, S.K.; Ahearne, M.; Mullins, R.; Hayati, B.; Schillewaert, N. Exploring the dynamics of antecedents to consumer-brand identification with a new brand. J. Acad. Mark. Sci. 2013, 41, 234-252. [CrossRef]

10. Urde, M.; Greyser, S.A. The corporate brand identity and reputation matrix-The case of the nobel prize. J. Brand Manag. 2016, 23, 89-117. [CrossRef]

11. Dressler, M.; Paunovic, I. Reaching for Customer Centricity-Wine Brand Positioning Configurations. J. Open Innov. Technol. Mark. Complex. 2021, 7, 1-21.

12. Ashforth, B.E.; Mael, F. Social Identity Theory and the Organization. Acad. Manag. Rev. 1989, 14, 20-39. [CrossRef]

13. Jin, L. A Brand Equity Driving Model Based on Brand Personality and Brand Identification. J. Beijing Technol. Bus. Univ. 2006, 1, 40-45.

14. Gong, Y.; Su, Z. Analysis of marketing strategy for brand fans in social network environment. J. Commer. Econ. 2016, 50-52.

15. Alba, J.W.; Hutchinson, J.W. Dimensions of Consumer Expertise. J. Consum. Res. 1987, 13, 411-454. [CrossRef]

16. Aaker, D. Measuring Brand Equity, Across Products and Markets. Calif. Manag. Rev. 1996, 38, 102-120. [CrossRef]

17. Zheng, N.; Huang, Z. The influence of consumer experience on brand loyalty in virtual brand community. J. Commer. Econ. 2018, 4, 76-78.

18. Cui, Z.; Chen, Y. An empirical study on the influence of offline experience characteristics on consumers' perceived value and patronage intention. Enterp. Econ. 2020, 2, 84-91.

19. Lee, S.H.; Han, S.L.; Jung, K.S. Analysis of the Structural Relationship between Antecedents and Outcomes of Brand Fanship. J. Mark. Manag. Res. 2015, 20, 133-153.

20. Pentecost, R.; Andrews, L. Fashion retailing and the bottom line: The effects of generational cohorts, gender, fashion fanship, attitudes and impulse buying on fashion expenditure. J. Retail. Consum. Serv. 2010, 17, 43-52. [CrossRef] 